\title{
EDUCAÇÃO DOMICILIAR: Direito Fundamental, Limites e Possibilidades Jurídicas
}

http://dx.doi.org/10.21527/2176-6622.2021.56.10173

Recebido em: 3/2/2020

Modificações solicitadas em: 18/11/2020

Aceito em: 9/2/2021

\section{Aristides Cimadon}

Autor correspondente. Universidade do Oeste de Santa Catarina. Rua Getúlio Vargas, 2125 - Flor da Serra. Joaçaba/SC, Brasil. CEP 89600-000. http://lattes.cnpq.br/2715888078959920. aristides.cimadon@unoesc.edu.br

Luiz Carlos Lückmann

Universidade do Oeste de Santa Catarina. Joaçaba/SC, Brasil.

\section{RESUMO}

O presente estudo tem por objetivo discorrer sobre as possibilidades e os limites jurídicos para legalizar a Educação Domiciliar no Brasil. Traz uma sucinta reflexão sobre o momento regulatório da educação brasileira e distingue os conceitos de educação, ensino, aprendizagem, instrução e escola. Em seguida, passa a conceituar a Educação Domiciliar como uma possibilidade de aprender, sem seguir rigidamente os programas escolares. É um tema controverso. Apesar da proibição regulatória, há inúmeras famílias, no Brasil, que optaram pela escolarização em casa. Ações judiciais, todavia, têm condenado os pais que praticam a homeschooling à litigância de "abandono intelectual". 0 texto discute os limites legais a partir dos ditames das leis brasileiras, além de tratados e convenções internacionais. Por fim, apresenta-se a possibilidade da regulação e normatização dessa modalidade de educação. Trata-se de estudo teórico, tendo como fontes a literatura, a legislação e documentos sobre a temática em discussão.

Palavras-chave: Educação; educação domiciliar; ensino; limites legais.

HOMESCHOOLING: FUNDAMENTAL RIGHTS, LIMITS AND LEGAL POSSIBILITIES

\section{ABSTRACT}

This study aimed to discuss the legal possibilities and limits for legalizing Home Education in Brazil. It brings a brief reflection on the regulatory moment of Brazilian education and distinguishes the concepts of education, teaching, learning, instruction, and school. Then it conceptualizes Home Education as a possibility to learn without strictly following school programs. It is a controversial subject. Despite the regulatory ban, there are countless families in Brazil who have opted for homeschooling. However, lawsuits have convicted parents who practice homeschooling to "intellectual abandonment" litigation. The text discusses the legal limits based on the dictates of Brazilian laws, as well as international treaties and conventions. Finally, it presents the possibility of the regulation and normalization of this modality of education. It is a theoretical study, having as sources the literature, legislations and documents on the subject under discussion.

Keywords: Education; home education; teaching; legal limits. 


\section{INTRODUÇÃO}

Antes de referenciar o tema central desse estudo, cujo escopo visa a discorrer sobre a escolarização em casa como um direito fundamental do cidadão e da família, é necessário definir algumas categorias, como educação, ensino, instrução e aprendizagem. Hoje, mais do que nunca, segmentos esclarecidos da sociedade estão mais conscientes da necessidade de inovação dos processos educacionais e reclamam oportunidades de educação dos filhos de modo diverso daquele da escolarização formal. Percebe-se que a instituição escolar, de modo geral, sobretudo aquela de natureza pública, tem dificuldades para realizar ensino e educação de qualidade. Sob essa constatação, muitas famílias desejam buscar alternativas para formação de seus filhos.

Entende-se, no presente estudo, que a escola é a instituição educacional construída e organizada, sob as regras do Estado, para oferecer ensino e possibilitar aprendizado do conhecimento, das habilidades intelectuais, sociais e motoras das pessoas, sejam elas crianças, adolescentes, jovens ou adultos. A escola é o espaço no qual se oferece o aprendizado por meio de trocas de conhecimento, de experiências ou por vários métodos e processos curriculares. É o local em que se realiza a instrução, a aprendizagem e a educação. Parece importante distinguir os conceitos entre ensino, aprendizagem, educação e instrução.

O ensino é um processo de transmissão de conhecimento que permite ao ser humano adquirir habilidades diversas, sejam intelectuais, sociais ou motoras. Pode-se distinguir três modalidades de ensino: formal, informal e não formal (KOWITZ; KOWITZ, 1969; FRABONI; MINERVA; TREBISACCE, 1992).

A aprendizagem, contudo, é um processo de aquisição de conhecimentos, habilidades, valores e atitudes, que passam a fazer parte do indivíduo, cuja aquisição ocorre pelo estudo, pelo ensino e pela experiência. A aprendizagem humana é definida como sendo a mudança relativamente estável do comportamento de um indivíduo como resultado da experiência (CIMADON, 2004).

A instrução, termo de origem no Latim (instructio), significa orientação, doutrinação pelo treinamento. A instrução tem relação com o ensino dirigido formal, cuja manipulação conduz a determinado objetivo pretendido. A educação é mais ampla, por que se relaciona ao conjunto do comportamento de um indivíduo. É a aquisição de habilidades, virtudes e vícios que definem a personalidade e o caráter de um indivíduo (GAGNÉ, 1980).

Embora a instituição escolar tenha o objetivo geral de educar, observa-se que está mais centrada no ensino, na instrução, na preocupação com o processo de aprendizagem de conhecimentos, nem sempre úteis à vida real. A escola, de fato, está estruturada para a escolarização, isto é, a instrução ou o processo de ensino e aprendizagem formal e atribui à família a responsabilidade de educar. O ordenamento jurídico brasileiro, contudo, estabelece, no artigo 205 da Constituição da República Federativa do Brasil de 1988, que "A educação, direito de todos e dever do Estado e da família, será promovida e incentivada com a colaboração da sociedade [...]" (BRASIL, 2019). A Lei de Diretrizes e Bases da Educação Nacional (LDB), por sua vez, prescreve, em seu artigo 2ㅇ, que "A educação, dever da família e do Estado, inspirada nos princípios de liberdade e nos ideais de solidariedade humana, tem por finalidade o pleno desenvolvimento do educando, seu preparo para o exercício da cidadania e sua qualificação para o trabalho" (BRASIL, 1996).

Considerando, portanto, a legislação vigente, assim como as perspectivas da tecnologia e da inovação e as novas formas de ensinar e de aprender, pergunta-se: Diante do direito fundamental da família de escolher a modalidade de educação de seus filhos, que limites e possibilidades jurídicas existem no Brasil para a concretização da homeschooling?

O presente estudo é de natureza teórica, fundamentado na legislação, em documentos oficiais, bem como em referencial de literatura especializada no assunto.

\section{ABORDAGENS CONCEITUAIS SOBRE EDUCAÇÃO DOMICILIAR}

Interessa, inicialmente, observar que "A educação estava longe de ser livre entre os gregos. Ao contrário, não havia nada em que o Estado fizesse mais do que ter a última palavra. Em Esparta, o pai não tinha nenhum direito sobre a educação do filho" (FUSTEL DE COULANGES, 2009, p. 23). Já em Roma era a família que conduzia a educação das crianças. O pai e a mãe tinham papéis distintos na formação dos filhos. Há, portanto, 
em Roma, uma importância fundamental na Educação Domiciliar. Houve, porém, grande modificação na educação romana ao tomar contato com a civilização grega, já no início do segundo século a.C.:

Evidentemente, a família não estava mais à altura de ministrar esta nova e mais elevada instrução (literária). As famílias das mais altas classes sociais hospedavam em casa um mestre, geralmente grego - pedagogus ou litteratus. E, para atender às exigências culturais e pedagógicas das famílias menos abastadas, vão-se, aos poucos, constituindo escolas - ludi - de instituição privada sem ingerência alguma do Estado (PADOVANI; CASTAGNOLA, 1972, p. 163).

Historicamente, a partir do Estado Moderno, o poder público foi regulando a educação por suas Constituições e leis. Não parece correto, todavia, que o Estado reduza o conceito de educação àquela formal e que somente sua diretriz seja concepção única de validade. A Educação Domiciliar, do ponto de vista legal de educação compartilhada com a família, tem perspectivas viáveis e necessárias.

Vista de uma perspectiva legal, o tema da Educação Domiciliar, no Brasil, foi debatido por Vieira (2012) em uma audiência pública da Câmara dos Deputados. Na ocasião, ficou evidente que a literatura sobre o assunto ainda é muito limitada. Demonstrou-se que a pesquisa mais consistente sobre Educação Domiciliar é feita nos Estados Unidos da América e na Europa. Vieira (2012) realizou sua pesquisa com 62 pais educadores de seus filhos em casa. Considera que os resultados de seus estudos são consistentes e em vários indicadores, quando adultos, os instruídos em casa possuem desempenho melhor que os escolarizados pela educação formal escolar.

A Educação Domiciliar é uma possibilidade de aprender sem seguir rigidamente os programas escolares, mediante um percurso mais personalizado. A Home School Legal Defense Association (HSLDA) tem organizado várias conferências mundiais sobre homeschooling, cujas conclusões apontam essa modalidade de educação dos filhos como um direito da família e uma possibilidade formativa que pode ter regulação estatal (BALENA, 2016).

A Educação Domiciliar oferece aos pais a possibilidade de oferta de formação de seus filhos, sem a necessidade de matriculá-los em uma escola de ensino regular. De acordo com Dias (2014, p. 27), diretor de Relações Institucionais da Associação Nacional de Ensino Domiciliar (Aned), a "Educação Domiciliar não é um método de ensino, não é a utilização de material didático específico, não é a prática de tirar uma criança da escola, não é uma ideologia ou filosofia fechada, mas uma oportunidade de aprender com ritmo próprio e atendimento personalizado".

Vieira (2012) destaca como a educação familiar tem crescido em diversos países, especialmente nos Estados Unidos, na África do Sul, na Rússia, no Reino Unido, no Canadá, na Austrália e na França. Também são realizados estudos na Itália, na Espanha e em outros países da Europa e da América Latina. A Rússia tinha proibição rígida da Educação Domiciliar, inclusive criminalizando seus adeptos, como é hoje no Brasil. Atualmente, porém, está regulamentada e em forte crescimento. Dados da Aned (2015) revelam que existem, no Brasil, cerca de 2.500 famílias cujos filhos estão em formação fora das instituições de ensino (SALLES; SANDOVAL, 2015).

Em razão da mobilidade social, da globalização profissional, das novas tecnologias e inovação e das modalidades de educação e novos tipos de educadores, hoje, mais do que no século passado, há necessidade de permitir diferentes formas de educar e de ensinar (CAVALI, 1992). Também, de acordo com o informativo Italia\&Orienta (2014), vários países europeus oficializaram a Educação Domiciliar e, sobretudo nos países anglo-saxões, já é uma prática rotineira. Assim, relata:

[...] em nosso país (Itália), na verdade, a Educação Domiciliar é pouco difundida. O Ministério da Educação menciona que há em torno de 100 famílias, porém estimativas não oficiais apontam para um pouco menos de mil, entretanto, esse fenômeno está consolidado no exterior, particularmente nos países anglo-saxões (nos EUA em torno de 2 milhões de famílias optam por educar em casa os próprios filhos, no Reino Unido são 70 mil, 60 mil no Canadá, 3 mil na França e 2 mil na Espanha) (ITALIA\&ORIENTA, 2014. p. 2, tradução livre).

Na Educação Domiciliar, o Estado atribui aos membros da família as funções de professores ou tutores dos próprios filhos, denominada, também, de educação parental. Sobre o assunto, Benoit (2016) cita que, na França, em torno de 30 mil crianças e jovens são escolarizados em casa, por um professor parente. Afirma que nesse país a instrução é obrigatória dos 6 aos 16 anos, porém não necessariamente essa obrigatoriedade deve ser cumprida na escola. Assim sendo, observa que: 
A escolaridade obrigatória pode ser oferecida em instituições ou escolas públicas ou privadas ou em famílias, pelos pais, ou um deles, ou por quem eles escolherem, nos termos legais. A instrução em casa é perfeitamente legal, devendo, em todos os anos, informar os resultados ao prefeito ou ao inspetor escolar (BENOIT, 2016. p. 7, tradução livre).

Nos Estados Unidos da América, tem crescido o interesse em homeschooling, especialmente nos meios fundamentalista e liberal, com argumentos que a escola força os alunos a suportar "autoridade irracional seis horas e meia por dia, cinco dias por semana...". Há desconfiança na esfera pública, que discrimina, faz bullying, pratica violência, oprime as crianças e jovens. Os homeschools americanos de todos os perfis acreditam que eles devem decidir como seus filhos devem ser educados (GOLDSTEIN, 2017, p. 5).

A situação na Espanha é mais complexa, porque os impedimentos para educar os filhos em casa são numerosos. O Informativo Magnet (2015) assim relata:

Na Espanha a prática da Educação Domiciliar é considerada exótica, minoritária e não tem amparo legal. A Educação Domiciliar, em nosso país, vive na clandestinidade, lutando, em cada caso perante a justiça e sobrevivendo em condições de precariedade. Mas, pode-se educar uma criança em casa, à margem da escola? Não somente se pode, como há milhares de famílias que manifestam, diariamente, esse desejo (MAGNET, 2015, 28 out, p. 8, tradução livre).

Segundo Martino (2017), várias razões levam as famílias a optarem pela educação familiar: motivos religiosos; impossibilidade de encontrar uma escola boa e próxima; maior liberdade; respeito à individualidade e ao ritmo do indivíduo; evitar os episódios de violência; evitar as pressões de grupos que levam à exposição ao fumo, droga, sexo precoce, bullying; obter melhores competências sociais; progredir mais rapidamente; aprofundar conhecimentos que não são tratados na escola; permitir estudos mais complexos, sem barreiras e limitações, a personalização da instrução.

De outro modo, vários estudiosos, sobretudo aqueles ligados aos órgãos estatais, mostram que a Educação Domiciliar é deficiente como formação integral e social, por mais escolarizados que sejam os pais. As tarefas dos pais já são muitas e, portanto, essa modalidade de instrução torna-se limitada, não permitindo que os filhos tenham condições de receber ensino formal adequado, sobretudo na aquisição de habilidades de conhecimento relacionados à Matemática, Física, Química e outras consideradas mais complexas.

As críticas mais comuns à educação em casa são formuladas nos seguintes termos: "Em casa, a criança não tem como trabalhar o aprendizado social" (ERAZO, 2010, tradução livre); "A mera relação em família dificilmente estimulará o completo desenvolvimento da personalidade da criança" (WEI, 2005, tradução livre); "Somente a escola proporciona conhecer pessoas de idades diferentes, culturas diferentes, com deficiências e diferentes habilidades, bem como pessoas e culturas de outros países" (ÁLVAREZ, 2008, tradução livre). "A questão que foi levantada por três profissionais ligados à educação -- em três continentes diferentes - é popularmente chamada de "a questão da socialização que a Educação Domiciliar não proporciona" (MEDLIN, 2000, tradução livre).

Vieira (2012) destaca três tipos básicos de educação em casa: a aprendizagem estruturada; a desescolarização (unschooling) e a aprendizagem eclética. O tipo unschooling é considerado aprendizagem autodirigida, aprendizagem dirigida pelo prazer (delight directed learning) ou método descontraído de Educação Domiciliar (relaxed home school method) e pesquisa independente. A estruturada é uma espécie de transposição do currículo escolar em casa e a eclética mistura os diversos tipos de metodologias. Em geral, os países regulamentam como deve ocorrer a Educação Domiciliar para os pais que a adotam.

Algumas famílias preferem seguir a programação diária, utilizando textos e currículos estruturados, outros querem confiar em uma aprendizagem mais natural e espontânea de acordo com as necessidades, interesses e habilidades das crianças como ajudantes e guias. Aqueles que escolhem educar em casa estão sujeitos à legislação do Estado, não às normas provinciais ou regionais, e um estudante pode completar todos os seus estudos (até a universidade), sem nunca pôr os pés numa sala de aula (ITALIA\&ORIENTA, 2014, tradução livre).

Interessa observar que, na maior parte dos casos na Educação Domiciliar, os professores são os pais ou parentes dedicados a essa atividade. Existem, porém, outras realidades, em que as famílias contratam 
um tutor ou professor para acompanhamento da escolarização dos seus filhos, fora da escola, obedecendo à regulação estatal. Algumas famílias compram sistemas de estudos, outras acompanham o currículo nacional e há ainda as que decidem com os filhos o programa a ser seguido. Algumas têm horários estipulados para as atividades, outras possuem dias e horários flexíveis (SALLES; SANDOVAL, 2015).

A legislação da educação brasileira não permite a Educação Domiciliar. Ao contrário, obriga, sob pena de punição, a educação escolar obrigatória dos 4 aos 17 anos, por determinação da Constituição da República Federativa do Brasil, artigo 208, I (1988) e da Lei de Diretrizes e Bases da Educação Nacional, Lei no 9.394/96, artigo 4으, I (1996), redação dada pela Lei no 12.796, de 2013.

\section{LIMITES E POSSIBILIDADES JURÍDICAS DA EDUCAÇÃO DOMICILIAR NA REPÚBLICA FEDERATIVA DO BRASIL: DIREITO FUNDAMENTAL?}

A Associação Nacional de Educação Domiciliar (Aned), afirma que, no Brasil, existem muitas famílias que respondem judicialmente por abandono intelectual, uma vez que não há admissão legal dessa modalidade de ensino. O Ministério da Educação não reconhece a Educação Domiciliar como um processo legal, porque interpreta que o ensino em casa fere o Estatuto da Criança e do Adolescente (ECA), a Lei de Diretrizes e Bases da Educação Nacional (LDB) e a Constituição da República Federativa do Brasil de 1988.

Esse entendimento, na visão da Aned, criminaliza pais e retira da família o direito fundamental de escoIher o tipo de educação para seus filhos. Sabe-se que o ordenamento jurídico brasileiro é um cipoal complexo, controvertido e antinômico. A perversa regulação da educação nacional, em todos os seus níveis, que conduz à tecnocracia dos órgãos públicos reguladores, insiste em desconsiderar a autonomia dos sistemas de ensino estaduais e municipais. Todo o aparato normativo educacional ainda traz incrustada a concepção centralizadora do Ministério da Educação. A legislação brasileira de educação e ensino conduz a um centralismo perverso e promotor da manutenção do subdesenvolvimento. Nesse sentido, Galvez (1986, p. 446) faz a seguinte observação:

O que mantém a situação de subdesenvolvimento não é só uma tradição e uma rotina. São, também, as leis, que tutelam e mantêm as relações econômicas, sociais e políticas que expressam essa situação atrasada. Por isso, o problema das relações entre sociedade e lei - sempre em tensão permanente em todos os lugares - se torna extremamente agudo no caso dos países subdesenvolvidos, quando estes se movem para romper as suas estruturas retrógradas.

A inflação normativa sobre educação, no Brasil, cada vez mais voraz, não tem melhorado os indicadores de avaliação. Nesse sentido, ecoam as palavras do saudoso professor Melo (2005, p. 2), encaminhadas em Parecer ao Conselho Estadual de Educação de Santa Catarina, quando respondia uma consulta àquele órgão normativo do Sistema de Ensino Estadual:

A centralização política, econômica e administrativa que ainda ocorre no Brasil, ao arrepio da matéria constitucional, é resultado de obscuras forças centrípetas que têm raízes longínquas no autoritarismo de nossas práticas coloniais e do período imperial, e, mais recentes, mas não menos prejudiciais à construção democrática, no coronelismo da Primeira República e nas oligarquias geradoras de privilégios que marcaram todo século XX. Tudo isso somado ao despreparo de uma população desprovida de sustentação educacional para reagir ao desmedido controle governamental em suas vidas, que vem abortando suas utopias e sua liberdade, têm gerado, ainda hoje, condições psicossociais para a imposição de regras autoritárias produzidas nos laboratórios da alquimia política de Brasília, sob os olhares permissivos, quando não cúmplices, de um Parlamento cuja maioria se agarra às benesses do poder central, a este se submetendo.

Também Pasold (2004, p. 162), ao se referir a Jorge Lacerda, aponta: [...] "a norma não pode estrangular a vida, nem as iniciativas da sociedade. O Direito deve modelar-se às realidades sociais e cristalizar os anseios da inquietação popular. Os formalismos estéreis que debilitam as novas proposições não são promotores do desenvolvimento".

Em verdade, o que se tem, no Brasil, em matéria de regulação sobre educação, sobretudo a partir de 1996, é uma inflação normativa centralizadora sem precedentes, que pode ser denominada de "entulho jurí- 


\section{Direito \\ Debate}

EDUCAÇÃO DOMICILIAR: DIREITO FUNDAMENTAL, LIMITES E POSSIBILIDADES JURÍDICAS

Aristides Cimadon - Luiz Carlos Lückmann

dico". Essa voraz regulamentação por Decretos, Portarias, Resoluções, Instruções Normativas e Notas Técnicas não significou instrumento de melhoria da qualidade da educação.

As atuais condições tecnológicas, as migrações dos povos, a mobilidade internacional do trabalho e a inovação estão exigindo flexibilização, abertura e múltiplas condições de aprendizado. Em muitos países, há a possibilidade de oferta de diversas modalidades de escolarização. Nesse aspecto, parece significativo citar Silvio (2000, p. 51), que destaca: "A evolução da humanidade tem criado necessidades que não podem ser satisfeitas vivendo, pensando e atuando sempre da mesma maneira e com os mesmos mecanismos físicos e cognitivos" (tradução livre). A pandemia da Covid19, com a experiência do ensino remoto e acompanhamento em casa, parece ter acelerado o desejo de muitas famílias sobre a regulação da Educação Domiciliar.

O ordenamento jurídico da educação brasileira estabelece que o Estado, por seus sistemas de ensino e instituições educacionais, tem o dever de escolarizar, isto é, oferecer educação formal. O que se quer defender aqui, contudo, é a possibilidade de que a educação formal também seja possível acontecer em casa, uma vez que a Constituição da República Federativa do Brasil de 1998 estabelece que a educação é dever do Estado e da família (artigo 205). Se é um dever, portanto, também é um direito de escolher a modalidade de educar.

A Constituição da República dos Estados Unidos do Brasil de 1937, artigo 125, estabelecia a educação familiar como primeiro direito e dever natural dos pais. Assim prescrevia: "A educação integral da prole é o primeiro dever e o direito natural dos pais". [...]

Da mesma forma, a Constituição dos Estados Unidos do Brasil de 1946 dava fundamental importância à educação familiar. Assim prescrevia o artigo 166 daquela Carta: "A educação é direito de todos e será dada no lar e na escola. Deve inspirar-se nos princípios de liberdade e nos ideais de solidariedade humana".

Já a Constituição da República Federativa do Brasil de 1988 trata da educação em um capítulo especial e, apesar do direito de todos, aponta o dever do Estado e da família em promovê-la. Assim reza o artigo 205:

Art. 205. A educação, direito de todos e dever do Estado e da família, será promovida e incentivada com a colaboração da sociedade, visando ao pleno desenvolvimento da pessoa, seu preparo para o exercício da cidadania e sua qualificação para o trabalho.

A educação, portanto, é um direito público subjetivo, um dever do Estado e da família. Ainda, em seu artigo 6으, a Constituição da República Federativa do Brasil de 1988 incluiu a educação como um direito fundamental social, que, no sentido stricto sensu, ampara a todos, sobretudo os menos favorecidos. A efetivação desse direito torna indispensável a existência de escola para todos. Isso significa que o indivíduo tem o direito de exigir do Estado o cumprimento da prestação educacional. Além disso, o artigo 208, I da Constituição Federal de 1988, estabelece a idade obrigatória dos 4 aos 17 anos de idade, assegurada a oferta gratuita nos estabelecimentos oficiais. O termo "educação" empregado no artigo 205 tem o sentido de educação formal ou escolarização (BULOS, 2002, p. 1.463).

Diante desse contexto legal, indaga-se: Se a educação é um dever também da família, como fica a liberdade de escolha do tipo de educação aos filhos? Por que a lei regula a obrigatoriedade da educação somente nos estabelecimentos escolares oficiais ou autorizados? 0 artigo 206 da Constituição da República Federativa do Brasil de 1988 parece indicar a condição de liberdade da família quanto ao tipo de escolarização como um direito fundamental social.

Constata-se, portanto, restrição de liberdade diante da obrigação da família na realização da matrícula de seus filhos em idade escolar somente em estabelecimentos formais de ensino. Embora a Constituição prescreva que a educação é "dever do Estado e da família", sua legislação infraconstitucional a qualifica e regula somente como um processo formal ou escolar "garantido" pelo Estado, não cabendo outra modalidade fora dele, sequer de forma excepcional, para atender a eventuais demandas particulares. Assim sendo, a responsabilidade da família limita-se a encaminhar seus filhos em idade escolar obrigatória à escola, como prescreve a LDB, Lei 9.394/96, nos artigos 2ㅇ a 70, impondo que é dever dos pais ou responsáveis efetuar a matrícula de crianças na Educação Básica a partir dos 4 anos de idade na escola regular, seja pública ou privada. Por sua vez o Estado, para efetivação da educação escolar pública, deverá garantir educação básica dos 4 aos 17 anos a todos os cidadãos. 
O Estado obriga-se a zelar, recensear e controlar a população em idade escolar, punindo os pais que não encaminharem seus filhos em idade escolar à instrução formal (escola). Nesse sentido, o Código Penal brasileiro, artigo 246, combinado com os artigos 55, 98, 100 e 101 do Estatuto da Criança e do Adolescente, Lei no 8.069/90, prevê detenção de 15 dias a um mês, ou multa, para quem deixar, sem justa causa, de prover a instrução primária de filho em idade escolar. É o que se considera "abandono intelectual". Conclui-se, portanto, que na atual regulação educacional brasileira não há espaço para a Educação Domiciliar.

O artigo 229 da Constituição da República Federativa do Brasil de 1988 prescreve que "os pais têm o dever de assistir, criar e educar os filhos menores [...]". Esta determinação encontra eco no artigo 1.634, I do Código Civil brasileiro, que prescreve: "Compete aos pais, quanto à pessoa dos filhos menores: I - dirigir-lhes a criação e educação". Então, por que não permitir às famílias a liberdade de educar? Em outros termos, por que o Estado não regula a Educação Domiciliar?

São várias as decisões de juízes das Varas Cíveis da Infância e da Juventude que, observando a atual legislação, condenaram os pais denunciados pelo Ministério Público, cujos filhos não frequentavam escola regular, sob a alegação de que, apesar de deterem o poder familiar, os pais não estão autorizados a retirar os filhos da rede regular de ensino para ensiná-los em casa. Exemplo é a decisão do juiz Marcos Flavio Lucas Padula, da Vara Cível da Infância e da Juventude de Belo Horizonte, em 2013, que alegou: "Sem uma legislação específica que regulamente o ensino domiciliar e estabeleça detalhadamente os critérios de ensino e avaliação do estudo no lar, [é] inviável que o poder Judiciário permita que os pais retirem os filhos das escolas" (PADULA, 2017).

De modo geral, os juízes têm decidido no sentido de entender que, apesar de a educação ser um dever do Estado e da família, os pais não podem restringir o direito fundamental social dos filhos à educação, tendo em vista o que dispõem os artigos 6 e 205 da Constituição da República Federativa do Brasil de 1988. Ademais, a mesma Constituição, artigos 206, 208, 210 e 214, impõe que o ensino obrigatório e a frequência à escola são indispensáveis, como prescreve a LDB de 1996. Nesse contexto, a alternativa do ensino domiciliar inexiste, legalmente, no Brasil. É dever dos pais assegurar a plenitude do acesso à educação e contribuir em máxima extensão para o desenvolvimento integral dos filhos, conforme estabelece o Estatuto da Criança e do Adolescente, em seus artigos 3우, 4우, 5ㅇ, 6으 e 56.

Em que pese essa visão do Ministério da Educação, dos órgãos públicos em geral e da maior parte das decisões judiciais e do Ministério Público, diversos educadores brasileiros e, sobretudo a Associação Nacional de Educação Domiciliar (Aned), têm divergente argumentação, no sentido de mostrar uma versão diferente daquela do Estado.

Em audiência pública realizada pela Comissão de Legislação Participativa, em 2013, para debater sobre Educação Domiciliar, Alexandre Magno Fernandes Moreira, diretor jurídico da Aned, argumenta que "a família não tem o direito de educar os filhos; a família tem o dever de educá-los". Sustenta que a norma internacional, cujos Tratados e Convenções foram referendados pelo Brasil, de certa forma autorizam as famílias brasileiras a optarem pela escolarização em casa. Assevera que a Declaração Universal dos Direitos Humanos, aprovada pela Organização das Nações Unidas (ONU) em 1948, artigo 26, item 3, destaca que a família tem prioridade de direito de escolher o tipo de educação a ser dado aos filhos. Da mesma forma, a Convenção sobre Direitos da Criança, recepcionada pelo Brasil em 1990, artigo 18, itens 1 e 2, assim prescreve: "Os Estados Partes envidarão os seus melhores esforços a fim de assegurar o reconhecimento do princípio de que ambos os pais têm obrigações comuns com relação à educação e ao desenvolvimento da criança. Caberá aos pais ou, quando for o caso, aos representantes legais, a responsabilidade primordial pela educação e pelo desenvolvimento da criança" [...].

A Convenção Americana sobre Direitos Humanos (Pacto de São José da Costa Rica), de 1969, promulgada no Brasil em 1992, artigo 12, item 4, assim reza: "Os pais, e quando for o caso os tutores, têm direito a que seus filhos ou pupilos recebam a educação religiosa e moral que esteja acorde com suas próprias convicções". Também o Pacto Internacional sobre Direitos Econômicos, Sociais e Culturais, ratificado pelo Brasil pelo Decreto no 591, de 6 de julho de 1992, artigo 13, 1, determina que "Os Estados Partes do presente Pacto se comprometem a respeitar a liberdade dos pais e, quando for o caso, dos tutores legais, de escolher para seus filhos escolas distintas daquelas criadas pelas autoridades públicas, sempre que atendam aos padrões mínimos de ensino prescritos ou aprovados pelo Estado" [...]. Ainda, o Pacto Internacional Sobre Direitos Civis e 
Políticos recepcionado no Brasil pelo Decreto 592, de 6 de julho de 1992, assim estabelece em seu artigo 18, item 4: "Os Estados Partes do presente Pacto comprometem-se a respeitar a liberdade dos pais e, quando for o caso, dos tutores legais - de assegurar a educação religiosa e moral dos filhos que esteja de acordo com suas próprias convicções".

Apesar da vigência desses pactos e da afirmação feita pelo Supremo Tribunal Federal, que os tratados internacionais sobre direitos humanos, em sua posição hierárquica, quando ratificados no Brasil, possuem valor constitucional, eles não têm eficácia sobre a regulação da educação nacional. A cultura e a prática jurídica brasileiras mostram que a eficácia da norma prospera, nunca no seu todo, apenas quando um comportamento é regulado por lei específica. Destarte, urge que, no Brasil, se regule essa possibilidade de a família optar pela Educação Domiciliar como uma modalidade de educação de seus filhos.

Diante desse entendimento, a Associação Nacional de Educação Domiciliar (Aned) tem procurado buscar regulamentação sobre o assunto. Está, portanto, tramitando, com aprovação na Comissão de Educação e Cultura da Câmara dos Deputados, o Projeto de Lei (PL) no 3.179/12-1 e a ele apensado o PL 3.261/2015, ambos de iniciativa legislativa. Os Projetos de Lei (PL) acrescentam parágrafo ao artigo 23 da LDB, Lei no 9.394, de 1996, para dispor sobre a possibilidade de oferta domiciliar da Educação Básica. A proposta tramita em caráter conclusivo e ainda será analisada pela Comissão de Constituição e Justiça e de Cidadania. O PL assim reza:

Art. 1 o 0 art. 23 da Lei no 9.394, de 20 de dezembro de 1996 passa a vigorar acrescido do seguinte parágrafo:

§3 É facultado aos sistemas de ensino admitir a educação básica domiciliar, sob a responsabilidade dos pais ou tutores responsáveis pelos estudantes, observadas a articulação, supervisão e avaliação periódica da aprendizagem pelos órgãos próprios desses sistemas, nos termos das diretrizes gerais estabelecidas pela União e das respectivas normas.

Art. 2ํ Esta lei entra em vigor na data de sua publicação.

Justificando a proposição dos PLs, argumenta-se que, por diversas vezes, proposições da instrução domiciliar foram negadas na Câmara dos Deputados. Há que se pensar, contudo, no princípio da liberdade e conceder a possibilidade de escolha da família para educação de seus filhos. Diz, ipsis literis:

É fato que, na realidade brasileira, a oferta desse nível de ensino se faz tradicionalmente pela via da educação escolar. Não há, porém, impedimento para que a mesma formação, se assegurada a sua qualidade e o devido acompanhamento pelo poder público certificador, seja oferecida no ambiente domiciliar, caso esta seja a opção da família do estudante. Garantir na legislação ordinária essa alternativa é reconhecer o direito de opção das famílias com relação ao exercício da responsabilidade educacional para com seus filhos.

Nesse sentido, apesar da existência e tramitação dos Projetos de Lei de iniciativa legislativa, o atual poder Executivo manifestou-se favorável à necessidade de regulação da oferta da Educação Domiciliar e, ainda em 2019, encaminhou PL ao Congresso Nacional, que tramita na Câmara dos Deputados, sob análise de Comissão Especial, sob o no 2.401/19. O PL de iniciativa do poder Executivo quer regulamentar de modo mais detalhado essa modalidade de educação no país.

Certamente, essa normatização futura poderá garantir as condições e requisitos para a oferta da escolarização em casa, obviamente com acompanhamento do Estado, cuja operacionalização deverá ocorrer pelos sistemas de ensino federal, estadual e municipal. Na Itália, por exemplo, as famílias que adotam a Educação Domiciliar devem demonstrar capacidade econômica e técnica para esse fim.

Por "capacidade técnica" compreende-se que aquele ou aquela que se encarrega da educação das crianças deve ter um nível maior de instrução do estudante (por isso, se a criança estuda para realizar os exames de quinta série, por exemplo, o pai ou tutor deve ter pelo menos o ensino médio) (CORRIEREUNIV.IT.Luglio 11th, 2014, tradução livre).

Com o desejo de encontrar amparo legal, há no Brasil inúmeros casos de famílias buscando na Justiça uma solução para a possibilidade da escola em casa, no entanto apenas um caso de Educação Domiciliar foi aprovado pela Justiça. Em Maringá (PR), o pedagogo Luiz Carlos Faria da Silva e a esposa Dayane podem educar em casa os filhos Lucas, 16 anos, e Julia, 15. Assim que não renovou a matrícula das crianças, em 2007, 
o casal foi denunciado. Após algumas audiências, o juiz liberou que os filhos estudassem em casa, mas com avaliações anuais e acompanhamento pedagógico e psicológico (RIBEIRO, 2015, p. 2).

Recente decisão do Recurso Extraordinário 888.815 (RE), entretanto, de repercussão geral, do Supremo Tribunal Federal (STF), que discutiu se a Educação Domiciliar pode ser considerada meio lícito de cumprimento do dever de prover a formação aos filhos, o relator do caso, ministro Luís Roberto Barroso, determinou a suspensão nacional de todos os processos em curso no poder Judiciário, tanto individuais como coletivos, que tratam sobre esse assunto.

A posição do STF no RE citado, contra a decisão monocrática do Juízo da Comarca de Canela e do Tribunal de Justiça do Rio Grande do Sul, que considerou válida a decisão da Secretaria Municipal de Educação de obrigar a matrícula escolar, reconhece repercussão geral e diz que "constitui questão constitucional saber se o ensino domiciliar (homeschooling) pode ser proibido pelo Estado ou viabilizado como meio lícito de cumprimento, pela família, do dever de prover educação, tal como previsto no Art. 205 da CRFN/88".

A recorrente fundamentou seu recurso no artigo 102, III, a da Constituição da República Federativa do Brasil de 1988 e alega violação aos artigos 205, 206, 208, 210, 214 e 229, todos da Constituição. Sustenta, em síntese, que,

restringir o significado da palavra educar simplesmente à instrução formal numa instituição convencional de ensino é não apenas ignorar as variadas formas de ensino - agora acrescidas de mais recursos com a tecnologia - como afrontar um considerável número de garantias constitucionais, cujo embasamento se dá, entre outros, pelos princípios da liberdade de ensino (art. 206, II, CF) e do pluralismo de ideias e de concepções pedagógicas (art. 206, III, CF), tendo-se presente a autonomia familiar assegurada pela Constituição (BRASIL. STF. Re no 888.815 RG/RGS. 2015. p. 2)

Discute-se, no caso, os limites relativos à liberdade dos pais na escolha dos meios para atender às determinações constitucionais (artigo 205) e da LDB (artigo 20), cuja efetivação é o dever conjunto do Estado e da família para cumprimento do direito fundamental à educação. Segundo a Aned, após o reconhecimento do Ministério da Educação da possibilidade de utilização da nota do Exame Nacional de Ensino Médio (Enem) como certificação da conclusão do Ensino Médio, em 2012, o número de adeptos da Educação Domiciliar tem aumentado significativamente no Brasil. Atualmente, esse exame foi remodelado para Exame Nacional para Certificação de Competências de Jovens e Adultos (Encceja).

O ministro Barroso (BRASIL, 2015), em sua argumentação, utiliza-se dos estudos do Sociólogo Vieira (2012), que considera que o caso representa repercussão geral, sobretudo do ponto de vista social, jurídico e econômico:

(i) social, em razão da própria natureza do direito pleiteado, tanto que previsto no art. 60, caput, c/c art. 205, da Constituição, como direito de todos e meio essencial ao exercício da cidadania e à qualificação para o trabalho; (ii) jurídico porque que relacionado à interpretação e alcance das normas constitucionais que preveem a liberdade de ensino e o pluralismo de ideias e concepções pedagógicas (art. 206, I e II da CFRB/1988), e bem como à definição dos limites da relação entre Estado e família na promoção do direito fundamental à educação e (iii) econômico, tendo em conta que, segundo os estudos acima citados, o reconhecimento do homeschooling poderia reduzir os gastos públicos com a educação (BRASIL - STF. Min. Barroso, 2015. p. 4).

Mais recentemente, em 12 de setembro de 2019, o Supremo Tribunal Federal julgou, definitivamente, o Recurso Extraordinário 888.815 (RE), decretando, por 9 votos contra 1, que a Educação Domiciliar no Brasil não deve ser admitida. O STF, todavia, não a declarou inconstitucional, isto é, a Constituição não proíbe, mas a legislação infraconstitucional não a admite, necessitando, portanto, ser regulamentada. O STF decidiu que não há direito líquido e certo para a Educação Domiciliar no Brasil. Alguns dos argumentos usados pelos ministros durante julgamento chegam a surpreender alguns analistas. Observa-se que, em muitas decisões recentes, há insistência do STF em legislar. Surpreendentemente, não foi o caso desse julgamento sobre homeschooling.

Em seus votos, a maioria dos ministros declarou-se em prol da constitucionalidade atrelada a uma necessidade de regulamentação. Em síntese, o STF posicionou-se, por maioria, que o ensino é obrigatório de 4 a 17 anos. Reforça que, nos termos do artigo 227 da Constituição, família, sociedade e Estado devem assegurar a crianças e adolescentes convivência familiar e comunitária. Assim sendo, não podem ser admitidas as moda- 
lidades de unschooling radical (desescolarização radical), unschooling moderada (desescolarização moderada) e modalidade de homeschooling puro. Essas modalidades de Educação Domiciliar negam a participação solidária do Estado que deve fixar os currículos básicos do processo de aprendizagem, bem como a supervisão decorrente. Para o STF, pode-se admitir, desde que regulada, a "homeschooling por conveniência circunstancial", isto é, quando esta modalidade de ensino privado individual se revelar "alternativa útil para prover os fins educacionais de modo tão ou mais eficiente que a escola" (ensino domiciliar "utilitarista").

O entendimento do STF, portanto, é de inconstitucionalidade de leis estaduais ou municipais sobre Educação Domiciliar. Há necessidade de prévia regulamentação nacional, em bases gerais, dessa modalidade de ensino pela legislação de diretrizes e bases da educação nacional. Certamente a homeschooling será uma realidade futura no Brasil, cuja qualidade, avaliação e planejamento dependerá muito de orientação dos sistemas de ensino federal, estadual e municipal.

\section{CONSIDERAÇÕES FINAIS}

O ordenamento jurídico sobre educação, no Brasil, apresenta-se como uma pletora de regras multifacetadas, contraditórias, antinômicas e promulgadas com certa resistência à autonomia dos sistemas de ensino federal, estadual e municipal. A União procura regular centralizando as decisões e possibilitando aos demais entes federados a legislação concorrente. Disso resulta uma inflação normativa de tamanho zelo que impressiona até quem pouco conhece do Direito Educacional.

A educação, no Brasil, é dever da família e do Estado, inspirada nos princípios de liberdade, entendida, essa categoria, como "instrução formal" oferecida de acordo com os regramentos da escolarização. Não há, a princípio, espaço para a Educação Domiciliar, de acordo com a atual legislação educacional específica brasileira. Essa restrição vem sendo questionada por vários estudiosos e famílias, sobretudo pela Aned que, a exemplo do que ocorre em inúmeros países, defendem a possibilidade de outorgar às famílias a opção de educar seus filhos em casa. Tomando como exemplo o êxito dessa modalidade educacional em vários países, a Aned alerta que as normas brasileiras referentes à educação contradizem as disposições dos Tratados e Convenções Internacionais ratificadas pelo Brasil e tolhem o princípio constitucional da liberdade e o poder familiar de decidir sobre a educação de seus filhos como direito fundamental.

Para dar garantia ao poder de liberdade e estabelecer o limite entre a autonomia da família e as imposições do Estado, seguem, na Câmara dos Deputados, os Projetos de Lei 3.179/12-1 e 3.261/215, de iniciativa legislativa, que propõem o acréscimo de um parágrafo ao artigo 23 de Lei 9.394/96 (LDB), facultando aos sistemas de ensino regular a Educação Básica Domiciliar. Apesar de esses projetos estarem tramitando desde 2019, por iniciativa do poder Executivo está tramitando o PL no 2.401/19, que tem por objetivo detalhar a regulação sobre o assunto.

O Supremo Tribunal Federal (STF) já se manifestou, decidindo pela constitucionalidade da modalidade de Educação Domiciliar, todavia atrelada a uma regulamentação geral nacional. Decidiu que a legislação brasileira obriga a educação escolar dos 4 a 17 anos e, nos termos do artigo 227 da Constituição, família, sociedade e Estado devem assegurar a crianças e adolescentes convivência familiar e comunitária. No entendimento do STF, pode-se admitir a Educação Domiciliar, desde que regulada e "por conveniência circunstancial", isto é, quando esta modalidade de ensino se revelar "alternativa útil para prover os fins educacionais de modo tão ou mais eficiente que a escola".

As motivações que levam as famílias a buscar a escolarização em casa são múltiplas. Em geral são de natureza religiosa, linguística, de saúde ou de pais que desejam dar a seus filhos uma educação diferenciada, insatisfeitos com a qualidade do ensino e com a metodologia da escola, para evitar a violência, a ideologização, o bullying, entre outras razões. Por outro lado, há muitas críticas à Educação Domiciliar, sobretudo com fundamento na privação das crianças e adolescentes da convivência social, da inaptidão dos pais ou tutores para ensinar com a qualidade necessária a uma formação adequada à competitividade.

Conclui-se, portanto, que a Educação Domiciliar no Brasil, sob a atual legislação, não é possível. É, todavia, um direito fundamental dos pais e das famílias escolherem a modalidade de educação que desejam para seus filhos e, portanto, a promulgação de legislação e de regulação específica sobre o assunto é medida necessária e urgente. 


\section{REFERÊNCIAS}

ÁlVAREZ, P. La casa no es una escuela. El País, 22 out. 2008. Disponível em: http://elpais.com/diario/2008/10/22/sociedad/1224626401_850215.html. Acesso em: 16 abr. 2018.

ANED. Associação Brasileira de Ensino Domiciliar. In: SALLES, Carol e SANDOVAL, Amanda. Fora da escola: conheça famílias que ensinam os filhos em casa. 2015. Disponível em: https://estilo.uol.com.br/.../fora-da-escola-conheça-familias-que-ensinam-os-filhos-em... Acesso em: 28 de março de 2017.

BALENA, Carlota. Ischool - II Futuro dela Scuola. 2016. Disponível em: http://ischool.startupitalia.eu/education/ 56938-20160907-homesch... Acesso em: 3 abr. 2017.

BENOIT, Julie. Faire L'école à la Maison: bonne ou mauvaise idée? Disponível em: http://www.magicmaman.com/,faire-I-ecole-a-I-maison-bonne-o... Acesso em: 30 mar. 2016.

BRASIL. Constituição da República dos Estados Unidos do Brasil de 1937. Disponível em: www.planalto.gov.br/ccivil_03/constituicao/constituicao37.htm. Acesso em: 21 abr. 2017.

BRASIL. Constituição dos Estados Unidos do Brasil de 1946. Disponível em: www.planalto.gov.br/ccivil_03/constituicao/constituicao46.htm. Acesso em: 21 abr. 2017.

BRASIL. Constituição 1988. Constituição da República Federativa do Brasil: promulgada em 5 de outubro de 1988. 21. ed. São Paulo: Saraiva, 2019.

BRASIL. Código Civil. Lei 10.406, de 10 de janeiro de 2002. In: SARAIVA. Vademecum. Colaboração Luiz Roberto Curia, Livia Céspide e Juliana Nicoletti. 16. ed. São Paulo: Saraiva, 2013a.

BRASIL. Código Penal. Decreto-Lei 2.848, de 7 de dezembro de 1940. In: SARAIVA. Vademecum. Colaboração Luiz Roberto Curia, Livia Céspide e Juliana Nicoletti. 16. ed. São Paulo, Saraiva, 2013 b.

BRASIL. Congresso Nacional. Câmara dos Deputados. Comissão de Legislação Participativa. Educação domiciliar. Brasília: Câmara dos Deputados; Edições Câmara, 2014. Disponível em: http://bd.camara.gov.br/bd/handle/bdcamara/17101. Acesso em: 12 abr. 2017.

BRASIL. Decreto no 99.710, de 21 de novembro de 1990. Convenção sobre os Direitos da Criança. Disponível em: www.planalto. gov.br/ccivil_03/decreto/1990-1994/d99710.htm. Acesso em: 10 abr. 2017.

BRASIL. Lei no 9.394, de 20 de dezembro de 1996 - Lei de Diretrizes e Bases da Educação Nacional. Disponível em: www.planalto.gov.br/ccivil_03/leis/L9394.htm. Acesso em: 5 abr. 2017.

BRASIL. Planalto. Decreto no 592, de 6 de julho de 1992. Pacto Internacional sobre Direitos Civis e Políticos. Disponível em: www.planalto.gov.br/ccivil_03/decreto/1990-1994/d0592.htm. Acesso em: 10 abr. 2017.

BRASIL. Supremo Tribunal Federal. Repercussão Geral no Recurso Extraordinário no 888.815 RG/RGS. Min. Roberto Barroso. Brasília. Decisão do Acórdão em 28 de maio de 2015. Documento assinado digitalmente conforme $\mathrm{MP} \mathrm{n}^{\circ} 2.200-2 / 2001$ de 24/8/2001, que institui a Infraestrutura de Chaves Públicas Brasileira - ICP - Brasil. O documento pode ser acessado no endereço eletrônico http://www.stf.jus.br/portal/autenticacao/ sob o número 8601165.

BULOS, Uadi Lammêgo. Constituição Federal - Anotada. 11. ed. São Paulo: Saraiva. 2016.

CAVALI, Alessandro. Insegnare Oggi. Bologna: II Molino, 1992.

CIMADON, Aristides. Ensino e aprendizagem na universidade: um roteiro de estudos. 2. ed. Joaçaba: Unoesc, 2004.

CORRIEREUNIV.IT. Mandare i figli a scuola? No grazie. Ecco cos'é l'educazione domiciliare. Luglio 11th, 2014. Disponível em: www.controscuola.it/faq/. Acesso em: 12 abr. 2017.

DIAS, Ricardo lene. Educação domiciliar. Brasília: Câmara dos Deputados; Centro de Documentação e Informação; Edições Câmara, 2014.

ERAZO, P. M. Ecuador: primeros casos de escuela en casa. BBC, Londres, 6 jun. 2010. Disponível em: http://www.bbc.co.uk/ mundo/cultura_sociedad/2010/06/100604_0224_ecuador_educacion_casa_l av.shtml>. Acesso em: 16 abr. 2018.

FERNANDES, Marcela. Fora da escola. Disponível em: www.correiobraziliense.com.br/.../ensino/...ensino/stf-decide-sobre-ensino-domicilia... 10 dez. 2016. Acesso em: 5 abr. 2017.

FERREIRA DE MELO, Osvaldo. Parecer. In: CIMADON, Aristides. Autonomia dos Estados Federados e Direito Educacional. Florianópolis: Conceito, 1997.

FRABONI, Franco; MINERVA, Franca Pinto; TREBISACCE, Giuseppe. Scuola 91. Roma-Bari: Editori Laterza, 1992.

FUSTEL DE COULANGES, Numa Denis. 1830-1889. A cidade antiga: estudo sobre o culto, o direito e as instituições da Grécia e de Roma. Tradução Roberto Leal Ferreira. São Paulo: Martin Claret, 2009. (Título original: La Cité Antique. Étude sur le culte, le droit, les institutions de la Grèce et de Rome).

GAGNÉ, Robert. Como se realiza a aprendizagem. Rio de Janeiro: Livros Técnicos e Científicos, 1980. 


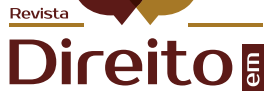 \\ Debate}

EDUCAÇÃO DOMICILIAR: DIREITO FUNDAMENTAL, LIMITES E POSSIBILIDADES JURÍDICAS

Aristides Cimadon - Luiz Carlos Lückmann

GALVEZ, Carlos. Manual de economia política atual. 10 ed. Rio de Janeiro: Forense Universitária, 1986.

GOLDSTEIN, Dana. Liberals, Don't Homeschool Your Kids - Why teaching children at home violates progressive values. Disponível em: http://www.slate.com/articles/double_x/doublex/2012/02/homesch... Acesso em: 31 mar. 2017.

ITALIA. Costituzione Della Repubblica Italiana. Disponível em: www.regione.taa.it/normativa/costituzione.pdf. Acesso em: 4 abr. 2017.

ITALIA\&ORIENTA. Mandare i figli a scuola? No grazie. Ecco cos'è l'educazione domiciliare. Luglio 11th, 2014. Disponível em: www.italiaorienta.it/.../mandare-i-figli-scuola-grazie-cose-leducaz. Acesso em: 29 mar. 2017.

KOWITZ, Geraldo T.; KOWITZ, Norma Giess. La Orientación Escolar em la Enseñanza Moderna. Buenos Aires: Editorial Troquel, 1969. 319 p. (Título original: Operating Guidance Services for the Modern School).

MAGNET. Blog informativo. Se puede educar a los niños en casa en España? 28 octubre, 2015 - MOHORTE. Disponível em: https://magnet.xataka.com/en-diez-minutos/se-puede-educar-a-los-ninos-en-casa-en-espana.

MARTINO, Erika Di. Mandere i Figli a scuola? No Grazie. Ecco cos'è l'educazione domiciliare. Blog, luglio 1th, 2014. Disponível em: http://correreuniv.it/cms/2014/07mandare-i-figli-scuola-gra... Acesso em: 31 mar. 2017.

MARTINO, Erika Di. Home schooling: l'educazione parentale in Italia. San Bernardino, CA: Create Space, 2017.

MEDLIN, R. Home schooling and the question of socialization. Peabody Journal of Education, 75, p. 107-123. 2000. Disponível em: https://peabody.vanderbilt.edu/journal/pje_volume_88_issue_3_2013/medlin.php. Acesso em: 16 abr. 2018.

MELO, Osvaldo Ferreira de. O Princípio Federativo e a Autonomia dos Sistemas de Ensino. Boletim Jurídico, ano 3, n. 132. Disponível em: HYPERLINK "http://www.boletimjurídico.com.br" www.boletimjurídico.com.br. Inserido em 2005; Acesso em: 16 de jun. 2017.

ONU. Organização das Nações Unidas. Declaração Universal dos Direitos Humanos. Disponível em: www.ohchr.org/EN/UDHR/ Documents/UDHR_Translations/por.pdf. Acesso em: 5 abr. 2017.

PADOVANI, Umberto; CASTAGNOLA, Luís. História da filosofia. 9. ed. São Paulo: Melhoramentos, 1972.

PADULA, Marcos Flávio Lucas. Processo n. 0024.16.093.949-2 - 06/04/2017 do TJMG. Vara Cível da Infância e da Juventude Comarca de Belo Horizonte. Publicado no Diário Judicial Eletrônico-DJE, 6.4.2017.

PASOLD, Cesar Luiz. Jorge Lacerda: uma vida muito especial. 2. ed. Florianópolis: OAB Editora; CLC Distribuidora de Livros, 2004.

RIBEIRO, Alice. Fugindo da escola. Disponível em: http://www.super.abril.com.br/comportamento/fugindo-da-escola. Acesso em: 28 mar. 2017.

SÃO JOSÉ DA COSTA RICA. Convenção Americana sobre Direitos Humanos. Disponível em: https://www.cidh.oas.org/basicos/ portugues/c.convencao_americana.htm. Acesso em: 10 abr. 2017.

SALLES, Carol; SANDOVAL, Amanda. Fora da escola: conheça famílias que ensinam os filhos em casa. 2015. Disponível em: https://estilo.uol.com.br/.../fora-da-escola-conheca-familias-que-ensinam-os-filhos-em... Acesso em: 28 mar. 2017.

SEDLMAYR, Agnes. O que é o unschooling? Livre para Crescer. Disponível em: www.livreparacrescer.com/2016/04/28/o-que-e-o-unschooling-2. Acesso em: 28 mar. 2017.

SILVIO, José. La virtualización de la Universidad. Caracas: lesalc/Unesco, 2000. 414 p.

VIEIRA, André de Holanda Padilha. "Escola? Não, obrigado": um retrato da homeschooling no Brasil. 2012. Monografia (Graduação do curso de Ciências Sociais, habilitação Sociologia) - Universidade de Brasília, UNB, Brasília, Instituto de Ciências Sociais, Departamento de Sociologia, 2012.

WEI, L. Children in home schooling face more problems. China Daily, 11 ago. 2005. Disponível em: http://www.chinadaily.com. cn/english/doc/2005-08/11/content_467993.htm. Acesso em: 20 abr. 2018. 